\title{
Association of Apolipoprotein A5 Polymorphism -1131T>C with Dyslipidemia in Suez Canal Area
}

\author{
Mohamed M. El-Shabrawi ${ }^{1}$ and Hussein A. Mahmoud ${ }^{2}$ \\ Departments of ${ }^{1}$ Clinical and Chemical Pathology, ${ }^{2}$ Cardiology, Faculty of Medicine, Suez Canal University, Egypt
}

\begin{abstract}
Aim: Polymorphisms in apolipoprotein A5 gene (APOA5) have been associated with higher triglyceride levels in many populations. The aim of this study was to determine the distribution of alleles and genotypes of the apoA5 $-1131 \mathrm{~T}>\mathrm{C}$ polymorphism, as well as to show the association of the genetic variant and the risk for the development of dyslipidemia among Egyptians. Patients and Methods: One hundred and fifty patients with dyslipidemia were included in this study. Additional 150 subjects without dyslipidemia served as a control group. ApoA5 $-1131 \mathrm{~T}>\mathrm{C}$ polymorphism was determined using PCR-RFLP technique. The total cholesterol, triglycerides, and HDL-C were determined enzymatically. Comparison of means among groups was calculated by ANOVA. Significant differences among groups were evaluated by Student-Newman-Keuls test. Results: The polymorphic allele $\mathrm{C}$ was found to be more frequent among subjects with dyslipidemia than control $(p=0.019)$. It imparts an additional individual risk factor for dyslipidemia (OR=1.7, 95\% IC=1.092.72). The polymorphic allele $C$ was more frequent among dyslipidemic males ( $O R=2.1,95 \%$ IC $=1.04-4.02, p=0.037$ ). Subjects carried the polymorphic allele $C$ (genotypes TC/ CC) showed higher cholesterol and triglycerides levels than subjects with genotype TT ( $p=0.042$ and 0.041 respectively). Conclusion: There is a strong association between ApoA5 -1131T>C and dyslipidemia. This association is more obvious among males.
\end{abstract}

Keywords: Apolipoprotein A, Dyslipidemia, Polymorphism

\section{Introduction}

World widely, dyslipidemia is one of the major health problems due to its high prevalence. Its association with serious medical conditions was well established such as hypertension, coronary artery diseases and stroke ${ }^{(1)}$. Causes and etiology of dyslipidemia are multiple and complex including environmental and genetic factors as well as their interactions ${ }^{(2,3)}$. In spite of the close relationship between dyslipidemia and coronary artery diseases, its underlying mechanisms remain unclear. Apolipoprotein $\mathrm{A}_{5}$ is identified as the newest member of apolipoproteins that participate in the homeostasis of plasma lipids ${ }^{(4,5)}$. Using a mouse model with overexpression of ApoA5, it was observed a marked reduction of very low-density lipoproteins (VLDL), triglycerides (TG) and $40 \%$ reduction in plasma total cholesterol (TC) concentrations. It was suggested that ApoA5 is involved in the processes regulating the plasma concentrations of TG and TC. Further studies showed that the protein is produced in the liver, but the biological function of APOA5 is not yet fully defined. The ApoA5was found predominantly bound to VLDL and HDL (high density lipoproteins) in the plasma ${ }^{(6,7)}$. Several groups have investigated the mechanisms 
underlying effects of ApoA5 on TG metabolism $^{(8,9)}$. The ApoA5 can inhibit the hepatic VLDL production, which can secondarily lower TG plasma concentrations ${ }^{(10)}$. Besides, ApoA5 can also activate the lipoprotein lipase, which enhances the intravascular TG hydrolysis. Both of these processes can be involved in the abnormal accumulation of lipids in the endothelial cells under pathologic conditions, ultimately in the formation of atherogenic plaques that are elements in obstructive vascular disease. The presence of naturally existing polymorphisms can modify the effect of ApoA5 on the lipid metabolism, which can result in increased TG concentrations ${ }^{(11)}$.

Additional studies have confirmed the association of ApoA $5-1131 \mathrm{~T}>C$ polymorphism rs 662799) with increased plasma TG concentrations in different populations, as in healthy Caucasians ${ }^{(5,10,11)}$, AfricanAmericans and Hispanics ${ }^{(12)}$. Studies have focused on the understanding of the molecular basis of atherosclerosis and its associated clinical manifestations and the characterization of the role of $\mathrm{ApoA}_{5}$ in this process. It was demonstrated that the polymorphism $-1131 \mathrm{~T}>\mathrm{C}$ is associated with increased risk of CAD for both Korean men and women, regardless of plasma APOA 5 level ${ }^{(13)}$. Similarly, this polymorphism was associated with increased susceptibility for developing $C A D$ in the Chinese population $^{(14)}$. Considering the importance of the polymorphism-1131T>C in ApoA5 gene in cholesterol and triglycerides metabolism, this study was conducted aiming to identify the frequency of this polymorphism and investigate its association with the lipid parameters in Egyptian dyslipidemic subjects and controls.

\section{Materials and Methods}

This case-control study included 150 dyslipidemic subjects and 150 normo- lipidemic (control) healthy volunteers, aged from 30 to 60 years, recruited at Suez Canal University hospital. The criteria for lipid and lipoprotein levels were according to the National Cholesterol Education Program $^{(15)}$. Participants were diagnosed with dyslipidemia if they had one or more of the following criteria: a plasma concentration of TC of $\geq 240 \mathrm{mg} / \mathrm{dl}$, plasma concentration of $\mathrm{TG} \geq 200 \mathrm{mg} / \mathrm{dl}$; plasma concentration of HDLC of $\leq 40 \mathrm{mg} / \mathrm{dl}$ for men or $\leq 50 \mathrm{mg} / \mathrm{dl}$ for women; and a plasma concentration of LDLC $\geq 160 \mathrm{mg} / \mathrm{dl}$.

The exclusion criteria included hyperglycemia or diabetes mellitus, hypothyroidism, renal, hepatic and autoimmune diseases, subjects treated with lipid-lowering drugs, oral anticoagulants and/or anti-inflammatory medications. Detailed information on cardiovascular risk factors, including hypertension, smoking, sedentary lifestyle, metabolic syndrome, and use of medicines were obtained from each individual. Hypertension was defined as blood pressure being $\geq 140 / 90 \mathrm{~mm} \mathrm{Hg}$, measured at two different occasions and/or use of antihypertensive medication. Those individuals who did not practice physical exercises regularly and for at least $40 \mathrm{~min}$, three times a week were considered seden$\operatorname{tary}^{(16)}$. NCEP criteria of the metabolic syndrome were defined as at least three of the following criteria: waist circumference $>102$ $\mathrm{cm}$ in men or $>88 \mathrm{~cm}$ in women, plasma triglycerides $\geq 150 \mathrm{mg} / \mathrm{dl}, \mathrm{HDL}$ cholesterol $\leq 40$ $\mathrm{mg} / \mathrm{dl}$ in men or $\leq 50 \mathrm{mg} / \mathrm{dl}$ in women, blood pressure $\geq 130 / 85 \mathrm{~mm} \mathrm{Hg}$, and fasting plasma glucose $\geq 110 \mathrm{mg} / \mathrm{dl}^{(15)}$. The study was approved by the Ethics Committee of the Suez Canal University, and carried out in accordance with the Helsinki Declaration. Informed consent was obtained from all participants after a full explanation of the study, and a complete clinical history was collected, including assessment of cardiovascular risk factors as obesity, smoking 
and hypertension. Venous blood samples were withdrawn after 12-14 $\mathrm{h}$ overnight fasting. Plasma TC, TG, HDLC and LDLC concentrations were measured using fullyautomated auto-analyzer Cobas 6000 (Roche Diagnostics, Boehringer, Mannheim, Germany). Apolipoprotein-A-I (apoA-I), apolipoprotein-B (apoB) and lipoprotein-a [LP(a)] were measured by immune-turbidimetric assays (Human ${ }^{\circledR}$, Human Diagnostics, Germany).

Genomic DNA was extracted using the commercially available Spin-column technique kit for DNA extraction from human whole blood (QIAamp®DNA Blood Mini Kit, QIAGEN, Valencia, CA, USA). The extracted DNA samples were stored at $-20^{\circ} \mathrm{C}$ for future use. Determination of APOA $5-1131 \mathrm{~T}>\mathrm{C}$ genotype was done using polymerase chain reaction ( $P C R$ ) using primers having the following sequences: The sense primer: F-5' GATTGATTCAACATGCATTTAG GAC 3' The anti-sense: R-5' CCCCAGGA ACTGGAG CGAAATT 3'. The PCR conditions were initially denaturing at $96^{\circ} \mathrm{C}$ for $10 \mathrm{~min}$, followed by 30 cycles of $94^{\circ} \mathrm{C}$ for $30 \mathrm{~s}, 58^{\circ} \mathrm{C}$ for $30 \mathrm{~s}, 72^{\circ} \mathrm{C}$ for $30 \mathrm{~s}$ and a final extension of 7 min at $72^{\circ} \mathrm{C}$. The $P C R$ products were digested for 8 hours at $37^{\circ} \mathrm{C}$ with the restriction enzyme Msel. The digested products were run on agarose gel (2.5\%) and stained with ethidium bromide.

\section{Statistical Analysis}

All values are expressed as mean \pm standard deviation (SD). Comparison of means among groups was calculated by analysis of variance (ANOVA). Statistically significant differences among groups were evaluated by Student-Newman-Keuls (SNK) test. $p$ Values lower than 0.05 were considered to carry significant differences. To estimate the relative risk of dyslipidemia associated with the presence of minor allele, an odds ratio (OR) with a corresponding 95\% confidence interval $(\mathrm{Cl})$ was calculated. Differences in allele and genotype frequencies between groups were compared by
Chi-square. The multivariate logistic regression was performed to investigate a possible association among risk factors, APOA 5 alleles and dyslipidemia. Statistical analyses were performed using SPSS/PC Statistical Package v.16.o (SPSS, Inc., Chicago, IL).

\section{Results}

The demographic characteristics and cardiovascular risk factors of control and dyslipidemic subjects are shown in Table 1. There were no significant differences for age, sedentary lifestyle, and smoking between dyslipidemic subjects and controls. These variables were not significantly different between case and control groups when adjusted according to gender. However, the dyslipidemic group presented higher BMI $(p=0.004)$, increased number of hypertensive subjects $(p=0.002)$ and of women in menopause $(p=0.003)$. In the dyslipidemic group, 24 individuals presented metabolic syndrome. The genotypes found in this group were: 8 participants TT, 10 CT and 6 CC. In each group, four individuals were male. No individual presented metabolic syndrome in control group (as individuals with metabolic syndrome were excluded from the beginning).

Comparing the ApoA5 $-1131 \mathrm{~T}>\mathrm{C}$ polymorphism allele frequency between the groups, it was observed that the polymorphic allele $C$ was more frequent in dyslipidemic subjects than controls ( $O R=1.7$, 95\% IC=1.09-2.72, $p=0.019)$. The analysis of the influence of $A p o A 5-1131 \mathrm{~T}>C$ polymorphism between the two groups by gender, showed that the polymorphic allele $C$ is more frequent in dyslipidemic male than control male $(\mathrm{OR}=2.1,95 \% \mathrm{IC}=1.04-4.02$, $\mathrm{p}=0.037)$. However, among women no significant difference was observed when compared the two groups ( $O R=1.5,95 \%$ $I C=0.79-2.94, p=0.202$ ). 
Table 1: Clinical and laboratory characters of study population

\begin{tabular}{|l|lll|}
\hline Item & Control & Patients & p-value \\
\hline - Age (years) (mean $\pm \mathrm{SD})$ & $45 \pm 5$ & $46 \pm 6$ & 0.081 \\
- Male $(\mathrm{N})$ & 65 & 88 & - \\
- Female $(\mathrm{N})$ & 85 & 62 & - \\
- BMI $\left(\mathrm{kg} / \mathrm{m}^{2}\right)$ & $24.6 \pm 5.2$ & $28.4 \pm 4.9$ & 0.004 \\
- Sedentary life $(\%)$ & $57 \%$ & $60 \%$ & 0.655 \\
- Smoking $(\%)$ & $18.8 \%$ & $21.2 \%$ & 0.721 \\
- Hypertension $(\%)$ & $11 \%$ & $35 \%$ & 0.002 \\
- Menopause $(\%)$ & $20 \%$ & $55 \%$ & 0.003 \\
- Total cholesterol $(\mathrm{mg} / \mathrm{dl})$ & $185 \pm 22$ & $235 \pm 45$ & 0.001 \\
- HDL-Cholesterol $(\mathrm{mg} / \mathrm{dl})$ & $54 \pm 12$ & $45 \pm 13$ & 0.001 \\
- LDL-Cholesterol $(\mathrm{mg} / \mathrm{dl})$ & $113 \pm 18$ & $176 \pm 41$ & 0.001 \\
- Triglycerides $(\mathrm{mg} / \mathrm{dl})$ & $102 \pm 41$ & $221 \pm 111$ & 0.001 \\
\hline
\end{tabular}

The genotype distribution (Table 2) showed higher frequency of TT in control group when compared to dyslipidemic group ( $p=0.007)$. The same association was observed in male group, but not in female individuals. It is worthy to emphasize that no homozygous subjects for the allele $C$ were observed in the male control group.

When the association between ApoA5 $-1131 \mathrm{~T}>\mathrm{C}$ polymorphism and lipid concentrations was evaluated, TC and TG concentrations were higher in C-carriers than TT homozygous ( $p=0.042$ and 0.041 , respectively) (Table 3). However, when this analy- sis was performed separately in dyslipidemic and controls groups, no significant differences for lipid concentrations was observed in each group, according to presence of the allele $C$. The logistic multivariate regression, considering the $\mathrm{ApoA}_{5}$ alleles and the risk factors as independent variables, showed that all of these variables were not independently associated with dyslipidemia: hypertension $(p=0.979), B M I$ $(p=0.891)$, smoking $(p=0.981)$, sedentary lifestyle $(p=0.996)$, ApoA5 polymorphism $(p=0.944)$, menopause $(p=0.979)$.

Table 2: Distribution of ApoA5 -1131T>C genotypes among study populations according to gender

\begin{tabular}{|c|lllll|}
\hline Genotype (Total) & Control $(\mathrm{n}=150)$ & Patients $(\mathrm{n}=150)$ & OR & $95 \% \mathrm{Cl}$ & $\mathrm{p}$-value \\
\hline TT & $100(66.7 \%)$ & $73(48.7 \%)$ & 0.52 & $0.32-0.832$ & 0.007 \\
TC & $45(30 \%)$ & $71(47.3 \%)$ & 2.16 & $1.21-3.271$ & 0.008 \\
CC & $5(3.3 \%)$ & $6(4 \%)$ & Reference & - & - \\
\hline Genotype (Male) & $\mathrm{n}=65$ & $\mathrm{n}=88$ & & & \\
TT & $44(67.7 \%)$ & $41(36 \%)$ & 0.44 & $0.211-0.945$ & 0.024 \\
TC & $21(32.3 \%)$ & $44(50 \%)$ & 2.21 & $0.877-4.567$ & 0.061 \\
CC & 0 & $3(4 \%)$ & Reference & - & - \\
\hline Genotype (Female) & $\mathrm{n}=85$ & $\mathrm{n}=62$ & & & 0.151 \\
TT & $54(63.5 \%)$ & $31(50 \%)$ & 0.524 & $0.252-1.231$ & 0.158 \\
TC & $27(31.8 \%)$ & $28(45.2 \%)$ & 2.011 & $0.907-4.321$ & - \\
CC & $4(4.7 \%)$ & $3(4.8 \%)$ & Reference & - & \\
\hline
\end{tabular}

$\mathrm{Cl}=$ confidence interval; OR=odds ratio, Significant level if $\mathrm{p}$-value $<0.05$ using Student $\mathrm{t}$-test

\section{Discussion}

This study was done aiming to determine frequency of the polymorphism $-1131 \mathrm{~T}>\mathrm{C}$ in ApoA5 gene as well as evaluate its association with the lipid parameters in dyslipidemic Egyptian subjects. Among the risk factors for cardiovascular diseases, an association between higher BMI and higher number of hypertensive and metabolic syndrome subjects was observed in the group of dyslipidemic individuals, as compared to controls. It is well known that overweight and hypertension are risk fac- 
tors frequently associated to dyslipidemia, further contributing for the increased incidence of $C A D^{(18-20)}$. Also, it is important to highlight that menopause; a factor associ- ated to development of dyslipidemia ${ }^{(21)}$ was more frequent among the dyslipidemic women included in this study.

Table 3: Lipid profile among different ApoA5
\begin{tabular}{|l|lll|}
\hline Parameter & TT & TC + CC & p-value \\
\hline - Total cholesterol $(\mathrm{mg} / \mathrm{dl})$ & $200 \pm 38$ & $213 \pm 46$ & 0.042 \\
- HDL-Cholesterol $(\mathrm{mg} / \mathrm{dl})$ & $52 \pm 14$ & $49 \pm 15$ & 0.521 \\
- LDL-Cholesterol $(\mathrm{mg} / \mathrm{dl})$ & $134 \pm 37$ & $149 \pm 46$ & 0.219 \\
- Triglycerides $(\mathrm{mg} / \mathrm{dl})$ & $132 \pm 112$ & $188 \pm 126$ & 0.041 \\
- Apolipoprotein A1 $(\mathrm{gm} / \mathrm{L})$ & $1.66 \pm 0.34$ & $1.58 \pm 0.47$ & 0.657 \\
- Apolipoprotein B $(\mathrm{gm} / \mathrm{L})$ & $0.78 \pm 0.22$ & $0.79 \pm 0.32$ & 0.291 \\
- Lipoprotein $(\mathrm{a})(\mu \mathrm{mol} / \mathrm{L})$ & $0.79 \pm 0.51$ & $0.82 \pm 0.62$ & 0.791 \\
\hline
\end{tabular}

The observed frequency for the ApoA 5 $-1131 \mathrm{C}$ allele among both dyslipidemic subjects and controls were comparable to that described in African-American and Hispanic $^{(10)}$, and French populations ${ }^{(22)}$, but lower than that in Chinese ${ }^{(23)}$ and Japanese populations ${ }^{(24)}$. The high $C$ allele frequency observed in dyslipidemic subjects compared to controls, has been previously described in other dyslipidemic groups ${ }^{(25-28)}$. In addition, Evans et al (2003) showed that $C$ allele frequency is significantly higher in patients with hypertrigliceridemia than those with hypercholesterolemia ${ }^{(34)}$. Altogether, these findings support the hypothesis that the $C$ allele of the ApoA5-1131T>C polymorphism affects the lipoprotein profile in dyslipidemic subjects.

In the present study, the presence of $C$ allele conferred about two folds increased individual risk for dyslipidemia when compared to $\mathrm{T}$ allele. This is in agreement with findings reported by Wang and coworkers $^{(3)}$. According to these authors, the ApoA $5-1131 \mathrm{~T}>C$ polymorphism is a marker for classic hyperlipoproteinemia phenotypes. In addition, the $-1131 \mathrm{C}$ allele was also associated with four folds increased individual risk for severe hypertriglyceridem$\mathrm{ia}^{(27)}$, and 2.38 fold increased risk for dyslipidemia in children and adolescents ${ }^{(25)}$. However, analyzing data by gender, this association was only observed among males, suggesting that the effect of the $C$ allele on development of dyslipidemia is gender-dependent. Olano-Martin et $\mathrm{al}^{(33)}$ observed that the impact of the $-1131 \mathrm{C}$ allele on fasting and postprandial triglyceride metabolism was only evident in the male participants ${ }^{(33)}$. Contrary, Komurcu-Bayrak et al demonstrated a gender-genotype association of $-1131 \mathrm{C}$ allele with dyslipidemia in Turkish women ${ }^{(38)}$. One possible explanation for these discrepancies is that sex steroid hormones act on several molecular loci that regulate lipoprotein metabolism, modulating the penetrance of individual gene variants ${ }^{(30)}$. Indeed, the impact of gender on genotype-lipoprotein associations has been reported previously as dependent of the number of genes and specific lipid cardiovascular disease risk factors $(32,33)$. Moreover, the menopausal status, with its known to impact on lipoprotein metabolism, may in part mask the effect of the ApoA5 genotype on lipid metabolism and explain the results observed in the present work, since menopause was more frequent among the dyslipidemic women.

The present study also showed an association between the ApoA $5-1131 \mathrm{~T}>\mathrm{C}$ polymorphism and increased plasma TG concentrations. This association has been investigated in different populations, but the results are inconsistent. No influence of $C$ allele on TG concentrations was observed 
in Brazilian children and adolescents ${ }^{(25)}$, as well as in different Chinese ethnic groups (34). However, Pennacchio et al reported an increased frequency of the rare $C$ allele in men with TG concentrations above the 9oth percentile, compared to the frequency in men with TG concentrations below the 10th percentile ${ }^{(12)}$. Guardiola and coworkers described that Caucasian boys carrying the $-1131 \mathrm{C}$ allele have a $12 \%$ increase in circulating TG concentrations and $7 \%$ decrease in HDLc concentrations ${ }^{(27)}$. It is remarkable in the literature that $\mathrm{C}$ allele influences TG concentrations in groups of patients with severe hyperlipoproteinemia phenotypes, as shown in familial combined hyperlipemia $^{(7)}$, type III hyperlipemia ${ }^{(26)}$ and severe hypertriglyceridemia ${ }^{(28,36)}$. According to Szalai et $\mathrm{al}^{(20)}$, the $-1131 \mathrm{C}$ allele does not produce categorical hypertriglyceridemia in most individuals, but acts as a modifier allele for plasma TG concentrations.

Despite the high consistency of the genotype-phenotype association observed by many studies, controversy remains regarding the association between $-1131 \mathrm{~T}>\mathrm{C}$ polymorphism and lipid metabolism. Possible explanations for these contradictory results include the finding that the frequencies of the minor allele differ among different ethnic populations. Moreover, environmental factors, i.e. diet, may vary among populations, playing a major role in the development of dyslipidemic diseases $^{(15)}$. Data of a collaborative analysis of 101 studies showed that $-1131 \mathrm{~T}>\mathrm{C}$ polymorphism is associated with higher VLDL concentrations and smaller HDL particle size, factors that could mediate the effects of $T G$ in $C A D^{(39)}$, which is consistent with a causal association between triglyceridemediated pathways and coronary heart disease. Concerning to TC, HDLC and LDLC fractions, the present study detected the association of $C$ allele only with higher TC concentrations, in agreement to other reports in different populations ${ }^{(26,20,39)}$. In contrast, in Japanese ${ }^{(26)}$, and in German hyperlipidemic subjects ${ }^{(35)}$, the $C$ allele did not influence TC concentrations.

Previous studies have shown the influence of $-1131 \mathrm{~T}>\mathrm{C}$ polymorphism on HDLC concentrations $^{(26,29,35,38,39)}$. A meta-analysis on this issue showed strong association of the $C$ allele with higher and lower concentrations of HDLC, respectively ${ }^{(39)}$. Moreover, in other studies, the $C$ allele did not affect HDLc concentrations, as shown in Caucasian population ${ }^{(5)}$, in Spanish patients with hyperlipidemia ${ }^{(39)}$ and in North American population. According to Jang et $\mathrm{al}^{(19)}$, this controversy in the literature may be related to the gender differences among studies. In a logistic regression analysis, the classic risks factors, hypertension, BMI, smoking, sedentary lifestyle and menopause were not independently associated to dyslipidemia. In addition, a lack of association between $-1131 \mathrm{~T}>\mathrm{C}$ polymorphism and dyslipidemia was seen in these analyses, suggesting that the polymorphism are not independently associated to dyslipidemia.

In conclusion, the present study showed that the allele $C$ confers higher TC and TC concentrations in dyslipidemic subjects. Furthermore, the ApoA5-1131 T $>C$ polymorphism is associated with increased risk for dyslipidemia in male subjects. These findings may be useful to a better characterization of the genetic risk factors for dyslipidemia and atherosclerotic diseases.

\section{References}

1. Yamada Y, Matsuo H, Warita S et al. Prediction of genetic risk for dyslipidemia. Genomics 2007; 90 (5), 551-558.

2. Choy PC, Siow YL, Mymin D, O K. Lipids and atherosclerosis. Biochem. Cell Biol 2004; 82 (1), 212-224. 
3. Wang J, Ban M, Kennedy B et al. APOA5 genetic variants are markers for classic hyperlipoproteinemia phenotypes and hypertriglyceridemia. Nat. Clin. Pract. Cardiovasc. Med 2008; 5 (11), 730-737.

4. Horínek A, Vráblík M, Ceska R, Adámková $\mathrm{V}$, Poledne R, Hubacek JA. T1131C polymorphism within the apolipoprotein AV gene in hypertriglyceridemic individuals. Atherosclerosis 2003; 167 (2), 369-370.

5. Peacock RE, Temple A, Gudnason V, Rosseneu $M$, Humphries $S \mathrm{E}$. Variation at the lipoprotein lipase and apolipoprotein AI-CIII gene loci are associated with fasting lipid and lipoprotein traits in a population sample from Iceland: interaction between genotype, gender, and smoking status. Genet. Epidemiol 1997; 14 (3), 265-282.

6. Jardim PC, Gondim Mdo R, Monego ET et al. High blood pressure and some risk factors in a Brazilian capital. Arq. Bras. Cardiol 2007; 88 (4), 452-457.

7. Pennacchio LA and Rubin EM. Apolipoprotein $\mathrm{A} 5$, a newly identified gene that affects plasma triglyceride levels in humans and mice. Arterioscler. Thromb. Vasc. Biol 2003; 23 (4), 529-534.

8. Mahley RW, Pépin J, Palaoğlu KE, Malloy MJ, Kane JP, Bersot TP: Low levels of high density lipoproteins in Turks, a population with elevated hepatic lipase. High density lipoprotein characterization and gender specific effects of apolipoprotein e genotype. J. Lipid Res 2000; 41 (8), 1290-1301.

9. Maturana MA, Irigoyen MC, Spritzer PM. Menopause, estrogens, and endothelial dysfunction: current concepts. Clinics (Sao Paulo) 2007; 62 (1), 77-86.

10. Pennacchio LA, Olivier M, Hubacek JA, Krauss RM, Rubin EM, Cohen JC. Two independent apolipoprotein $A_{5}$ haplotypes influence plasma triglyceride levels. Hum. Mol. Genet 2002; 11 (24), 3031-3038.

11. Talayero BG and Sacks FM. The role of triglycerides in atherosclerosis. Curr. Cardiol. Rep 2011; 13 (6), 544-552.

12. Pennacchio LA, Olivier M, Hubacek JA et al. An apolipoprotein influencing triglycerides in humans and mice revealed by compara- tive sequencing. Science 2001; 294 (5540), 169-173.

13. Huang XS, Zhao SP, Zhang Q, Bai L, Hu M. Association of plasma apolipoprotein AV with lipid profiles in patients with acute coronary syndrome. Atherosclerosis 2009; 204 (2), e99-e102.

14. Lauer $M$ and Fontanarosa P: NCEP - National Cholesterol Education Program. Executive Summary of The Third Report of The National Cholesterol Education Program Expert panel on detection, evaluation, and treatment of high blood cholesterol in adults (Adult Treatment Panel III). Updated guidelines for cholesterol management. Jama 2001; 285 (19), 2486-2497.

15. Lai CQ, Parnell LD, Ordovas JM. The APOA $1 / C_{3} / A_{4} / A_{5}$ gene cluster, lipid metabolism and cardiovascular disease risk. Curr. Opin. Lipidol 2005; 16 (2), 153-166.

16. Sousa $\quad M Q$, Alía $\quad P$, Pintó $\quad X$, Corbella $E$, Navarro MA. Interaction between APOA5-1131T>C and APOE polymorphisms and their association with severe hypertriglyceridemia. Clin. Chim. Acta 2008; 395 (12), 68-71.

17. Araújo F, Yamada AT, Araújo MV, Latorre Mdo R, Mansur AJ. Lipidic profile of individuals without cardiopathy with overweight and obesity. Arq. Bras. Cardiol 2005; 84 (5), 405-409.

18. Jang Y, Paik JK, Hyun YJ et al. The apolipoprotein $\mathrm{A} 5-1131 \mathrm{~T}>\mathrm{C}$ promoter polymorphism in Koreans: association with plasma APOA5 and serum triglyceride concentrations, LDL particle size and coronary artery disease. Clin. Chim. Acta 2009; 402, 83-87.

19. Szalai C, Keszei M, Duba J et al. Polymorphism in the promoter region of the apolipoprotein $\mathrm{A} 5$ gene is associated with an increased susceptibility for coronary artery disease. Atherosclerosis 2004;173 (1), 109114.

20.Matsunaga $\mathrm{A}$, Arishima $\mathrm{H}$, Niimura $\mathrm{H}$ et al. Strong linkage disequilibrium and association of $-1131 \mathrm{~T}>\mathrm{C}$ and $\mathrm{C} .553 \mathrm{G}>\mathrm{T}$ polymorphisms of the apolipoprotein $A 5$ gene with hypertriglyceridemia in a Japanese population. Circ. J 2007; 71 (5), 746-752. 
21. Charriere $S$, Bernard $S$, Aqallal $M$ et al. Association of APOA5-1131T>C and S19W gene polymorphisms with both mild hypertriglyceridemia and hyperchylomicronemia in type 2 diabetic patients. Clin. Chim. Acta 2008; 394 (1-2), 99-103.

22. Li YY, Yin RX, Lai CQ et al. Association of apolipoprotein $\mathrm{A} 5$ gene polymorphisms and serum lipid levels. Nutr. Metab. Cardiovasc. Dis 2011; 21 (12), 947-956.

23. Maász A, Kisfali P, Szolnoki Z, Hadarits F, Melegh B: Apolipoprotein A5 gene $\mathrm{C}_{56 \mathrm{C}}$ variant confers risk for the development of large-vessel associated ischemic stroke. J. Neurol 2008; 255 (5), 649-654.

24. Brito DD, Fernandes AP, Gomes KB et al. Apolipoprotetein $A 5-1131 \mathrm{~T}>C$ polymorphism, but not APOE genotypes, increases susceptibility for dyslipidemia in children and adolescents. Mol. Biol. Rep 2011; 38 (7), 4381-4388.

25. Endo K, Yanagi H, Araki J, Hirano C, Yamakawa-Kobayashi K, Tomura S. Association found between the promoter region polymorphism in the apolipoprotein A-V gene and the serum triglyceride level in Japanese schoolchildren. Hum. Genet 2002; 111 (6), 570-572.

26. Guardiola M, Ribalta J, Gómez-Coronado D , Lasunción MA, de Oya $M$, Garcés C. The apolipoprotein A5 (APOA5) gene predisposes Caucasian children to elevated triglycerides and vitamin E (Four Provinces Study). Atherosclerosis 2010; 212 (2), 543-547.

27. Sarwar N, Sandhu M, Ricketts S et al: Triglyceride-mediated pathways and coronary disease: collaborative analysis of 101 studies. Lancet 2010; 375 (9726):, 1634-1639.

28. Talmud PJ, Hawe E, Martin S et al: Relative contribution of variation within the $A P O C_{3} /$ $\mathrm{A} 4 / \mathrm{A} 5$ gene cluster in determining plasma triglycerides. Hum. Mol. Genet 2002; 11 (24), 3039-3046.

29. Nabika T, Nasreen S, Kobayashi S, Masuda J et al: The genetic effect of the apoprotein AV gene on the serum triglyceride level in Japanese. Atherosclerosis 2002; 165 (2), 201-204.

30.Kluger M, Heeren J, Merkel M: Apoprotein A-V: an important regulator of triglyceride metabolism. J. Inherit. Metab. Dis 2008; 31(2), 281-288.

31. Liu H, Zhang S, Lin J et al: Association between DNA variants sites in the apolipoprotein $\mathrm{A} 5$ gene and coronary heart disease in Chinese. Metabolism 2005; 54 (5), 568-572.

32. Olano-Martin E, Abraham EC, Gill-Garrison R et al. Influence of apoA- $V$ gene variants on postprandial triglyceride metabolism: impact of gender. J. Lipid Res 2008; 49 (5), 945-953.

33. Li G, Wang JY, Yan SK, Chen BS, Xue H, Wu $G$. Genetic effect of two polymorphisms in the apolipoproteín $A_{5}$ gene and apolipoproteín $\mathrm{C}_{3}$ gene on serum lipids and lipoproteins levels in a Chinese population. Clin. Genet 2004; 65 (6), 470-476.

34. Evans D, Buchwald A, Beil FU. The single nucleotide polymorphism $-1131 \mathrm{~T}>C$ in the apolipoprotein A5 (APOA5) gene is associated with elevated triglycerides in patients with hyperlipidemia. J. Mol. Med. (Berl.) 2003; 81 (10), 645-654.

35. Yin RX, Li YY, Liu WY, Zhang L, Wu JZ. Interactions of the apolipoprotein a5 gene polymorphisms and alcohol consumption on serum lipid levels. PLoS One 2011; 6 (3), e17954

36.Sposito AC, Caramelli B, Fonseca FA et al: IV Brazilian Guideline for dyslipidemia and atherosclerosis prevention: Department of Atherosclerosis of Brazilian Society of Cardiology. Arq. Bras. Cardiol 2007; 88 (suppl 1), 2-19.

37. Komurcu-Bayrak E, Onat A, Poda $M$ et al. Gender-modulated impact of apolipoprotein A5 gene (APOA5) $-1131 \mathrm{~T}>\mathrm{C}$ and $\mathrm{C} .56 \mathrm{C}>\mathrm{C}$ polymorphisms on lipids, dyslipidemia and metabolic syndrome in Turkish adults. Clin. Chem. Lab. Med 2008; 46 (6), 778-784.

38. Ribalta J, Figuera L, Fernández-Ballart J et al. Newly identified apolipoprotein AV gene predisposes to high plasma triglycerides in familial combined hyperlipidemia. Clin. Chem 2002; 48 (9), 1597-1600.

39.Zhao $T$ and Zhao J: Association of the apolipoprotein $\mathrm{A} 5$ gene $-1131 \mathrm{~T}>\mathrm{C}$ polymorphism with fasting blood lipids: a metaanalysis in 37859 subjects. BMC Med. Genet 2010; 11, 120. 